\title{
The Benefit of Baseline Staging-Risk Assessment of Distant Breast Cancer Metastases by Tumor Stage
}

\author{
NELMIN RIOS ${ }^{1}$, NINA ADASKINA ${ }^{2}$, CORNELIA FRÖMKE $^{2}$, FRANK PAPENDORF $^{3}$, CORDULA SCHIPPERT $^{1}$, \\ ARMIN KOCH ${ }^{2}$, PETER HILLEMANNS ${ }^{1}$ and TJOUNG-WON PARK-SIMON ${ }^{1}$ \\ ${ }^{1}$ Department of Obstetrics and Gynecology, ${ }^{2}$ Institute for Biometry, and \\ ${ }^{3}$ Cancer Registry, Hannover Medical School, Hannover, Germany
}

\begin{abstract}
Background: Despite recommendations of international societies, use of baseline staging in breast cancer varies considerably. We retrospectively analyzed the prevalence of metastases in each pTN stage to estimate the benefit of staging. Patients and Methods: The prevalence of metastases at primary diagnosis (M1) and in the first year after diagnosis $\left(\mathrm{MI}_{12}\right)$ was determined in 2,906 patients. Results: The prevalence of $M 1$ was $0.95 \%$ [95\% confidence interval $(C I)=0.53-1.70 \%]$ in $p T 1 p N O, 2.17 \% \quad(95 \%$ $C I=1.00-4.64)$ in $p T 1 p N 1$ and $1.53 \%(95 \% C I=0.78-2.99 \%)$ in $p T 2 p N O$. The prevalence of $M 1_{12}$ was $2.17 \%(95 \%$ $C I=1.47-3.18 \%)$ in $p T 1 p N O$ and $3.25 \%$ in pathological stage IIA (upper confidence bound 5.14\%). In pT2pN1 the prevalence of $M 1$ and $M 1_{12}$ was $3.49 \%$ (95\% CI=1.96$6.14 \%$ ) and $6.35 \%(95 \% C I=4.15-9.60 \%)$, respectively. Results for stage $p T 3 p N O$ and higher were inconclusive. Conclusion: Baseline staging can be safely abandoned in pathological stage I and IIA. Individual decisions should be made for pT2pN1. Staging is recommended in stages of pT3pNO or higher.
\end{abstract}

In patients with newly diagnosed breast cancer, accurate assessment of the extent of locoregional and distant tumor is considered crucial for treatment planning. In general, staging work-up includes bone scan, liver ultrasonography and chest radiography. More recently, chest computed tomography (CT), abdominal CT/ultrasound and bone scans are recommended $(1,2)$. Several studies demonstrated that the prevalence of detectable metastases at initial diagnosis is very low in most stages of the disease $(3,4)$. Hence, routine

Correspondence to: Professor Dr. T. W. Park-Simon, Department of Obstetrics and Gynecology, Hannover Medical School, Hannover, Germany. Tel: +49 5115329545, Fax +49 5115326039, e-mail: park-simon.tjoung-won@mh-hannover.de

Key Words: Breast cancer, baseline staging, metastasis, tumor stage. staging work-up is not recommended for all patients and is considered inappropriate for asymptomatic patients with small tumors and minimal nodal involvement. Despite available guidelines, routine use of baseline staging in breast cancer still varies considerably, with some patients still undergoing extensive staging. This situation is complicated by the fact that practical guidelines vary across leading international and national professional societies $(3,5)$.

The clinical practice guideline of the European Society for Medical Oncology recommends baseline radiological staging for patients with clinically positive axillary nodes, large tumors $(e . g . \geq 5 \mathrm{~cm})$ or symptomatic tumors (2). According to the current guideline of the National Comprehensive Cancer Network, staging should be considered for patients with clinical stage IIIA and higher, but not for asymptomatic patients with stage I-IIB disease (1). Instead, the Breast Cancer Disease Site Group Ontario Cancer Care recommends routine bone scan in patients with pathological stage II tumors (3). Routine liver ultrasonography and chest radiography are not recommended in this group but could be considered in patients with four or more positive lymph nodes. Complete baseline staging is recommended as part of the postoperative baseline staging in those with pathological stage III tumors (3). In contrast, the German interdisciplinary S3 guideline advises against oncological staging in patients with T1N0 and T2N0 tumors only (5).

Although it is generally accepted that the yield of baseline staging increases with tumor stage, the prevalence of distant metastasis in the subgroups of each pathological tumor stage is unclear. In particular, the role of baseline staging tests in stage II breast cancer remains controversial, since the prevalence of metastases seems to vary significantly across this subgroup.

To our knowledge, this is the largest retrospective study aiming to identify subgroups of patients with asymptomatic primary breast cancer at different levels of risk for distant metastasis. The primary goal of this study was to determine the prevalence of distant metastasis for each subgroup of 
Table I. Proportion of patients with metastases at initial diagnosis (M1). Numbers of patients with $M 0, M 1$ or MX are listed dependent on the $p T$ and $\mathrm{pN}$ classification. The proportion of $\mathrm{MI}$ and $\mathrm{MX}$ as well as the corresponding two-sided 95\% Wilson confidence intervals (CI) are presented.

\begin{tabular}{lcccccc}
\hline $\begin{array}{l}\text { Tumor } \\
\text { stage }\end{array}$ & $\begin{array}{c}\mathrm{M} 0, \\
\mathrm{n}\end{array}$ & $\begin{array}{c}\mathrm{M} 1, \\
\mathrm{n}\end{array}$ & $\begin{array}{c}\mathrm{MX}, \\
\mathrm{n}\end{array}$ & $\begin{array}{c}\text { Sum, } \\
\mathrm{n}\end{array}$ & $\begin{array}{c}\text { M1 and } \\
\mathrm{MX}\end{array}$ & $95 \% \mathrm{CI}$ \\
\hline pT1pN0 & 1142 & 3 & 8 & 1153 & $0.95 \%$ & $0.53-1.70 \%$ \\
pT1pN1a & 271 & 6 & 0 & 277 & $2.17 \%$ & $1.00-4.64 \%$ \\
pT1pN2a & 55 & 3 & 0 & 58 & $5.17 \%$ & $1.77-14.14 \%$ \\
pT1pN3a & 37 & 8 & 4 & 49 & $24.49 \%$ & $14.60-38.09 \%$ \\
pT1pN3c & 0 & 2 & 0 & 2 & $100.00 \%$ & $34.24-100.00 \%$ \\
pT2pN0 & 515 & 5 & 3 & 523 & $1.53 \%$ & $0.78-2.99 \%$ \\
pT2pN1a & 304 & 10 & 1 & 315 & $3.49 \%$ & $1.96-6.14 \%$ \\
pT2pN2a & 151 & 9 & 3 & 163 & $7.36 \%$ & $4.26-12.43 \%$ \\
pT2pN3a & 107 & 8 & 0 & 115 & $6.96 \%$ & $3.57-13.13 \%$ \\
pT3pN0 & 29 & 0 & 1 & 30 & $3.33 \%$ & $0.59-16.67 \%$ \\
pT3N1a & 25 & 0 & 0 & 25 & $0.00 \%$ & $0.00-13.32 \%$ \\
pT3pN2a & 31 & 2 & 1 & 34 & $8.82 \%$ & $3.05-22.96 \%$ \\
pT3pN3a & 43 & 7 & 1 & 51 & $15.69 \%$ & $8.17-28.01 \%$ \\
pT4pN0 & 29 & 2 & 0 & 31 & $6.45 \%$ & $1.79-20.72 \%$ \\
pT4pN1a & 21 & 3 & 0 & 24 & $12.50 \%$ & $4.34-31.00 \%$ \\
pT4pN2a & 17 & 2 & 1 & 20 & $15.00 \%$ & $5.24-36.04 \%$ \\
pT4pN3a & 26 & 8 & 1 & 35 & $25.71 \%$ & $14.16-42.07 \%$ \\
pT4pN3b & 0 & 1 & 0 & 1 & $100.00 \%$ & $20.65-100.00 \%$ \\
\hline
\end{tabular}

pathological tumor stage. In addition, a multivariate analysis was performed to evaluate the prognostic value of tumor stage to other clinically important covariables.

\section{Patients and Methods}

This retrospective study included 2906 asymptomatic patients with newly diagnosed breast cancer who were referred to the Hannover Medical School between 1992-2009. Since the early 1980s, the Cancer Registry, Hannover Medical School, has recorded all patients with breast cancer who were referred to the Department of Obstetrics and Gynecology. Patient and tumor characteristics were documented based upon the medical records. Follow-up data were obtained by retrieving subsequent patient contact documented in the medical information system of the Hannover Medical School. The system includes information from practitioners and appropriate registration offices.

In this study, only patients with known pathological $\mathrm{T}$ and $\mathrm{N}$ status were included. Staging was allocated according to the sixth edition of the TNM staging system of the American Joint Committee on Cancer (6). All patients who received neoadjuvant therapy were excluded from this study. The majority of the patients underwent baseline staging including bone scan, liver ultrasonography and chest radiography. More recently, chest and abdominal computed tomographic scans were preferentially used. Missing or incomplete data (i.e. MX, missing HER2/neu and hormone receptor status, grading) are mainly due to the retrospective nature of the analysis.

The prevalence of metastases at initial diagnosis (M1) in the first 12 months of follow-up after primary diagnosis $\left(\mathrm{M}_{12}\right)$ was determined. All cases of MX were classified as M1. The analysis of
Table II. Proportion of metastases at 12 months' follow-up (M1 12$)$. Three categories of metastasis are distinguished: no distant metastasis (MO), distant metastasis $\left(\mathrm{M1}_{12}\right)$ and $M$ status unknown/indeterminate $(M X)$. Numbers of patients with $M 0, M 1_{12}$ or $M X$ are listed dependent on the $\mathrm{pT}$ and $\mathrm{pN}$ classification. The proportion of $M 1_{12}$ and $M X$ as well as the corresponding two-sided $95 \%$ Wilson confidence intervals (CI) are presented.

\begin{tabular}{|c|c|c|c|c|c|c|}
\hline & $\begin{array}{c}\text { M0 } \\
\mathrm{n}\end{array}$ & $\underset{\mathrm{n}}{\mathrm{M} 1_{12},}$ & $\underset{\mathrm{n}}{\mathrm{MX}}$ & $\begin{array}{c}\text { Sum, } \\
n\end{array}$ & $\begin{array}{c}\mathrm{M} 1_{12} \text { and } \\
\mathrm{MX}\end{array}$ & $95 \% \mathrm{CI}$ \\
\hline $\mathrm{pT} 1 \mathrm{pN} 0$ & 1128 & 19 & 6 & 1153 & $2.17 \%$ & $1.47-3.18 \%$ \\
\hline pT1pN1a & 267 & 10 & 0 & 277 & $3.61 \%$ & $1.97-6.52 \%$ \\
\hline $\mathrm{pT} 1 \mathrm{pN} 2 \mathrm{a}$ & 55 & 3 & 0 & 58 & $5.17 \%$ & $1.77-14.14 \%$ \\
\hline pT1pN3a & 37 & 11 & 1 & 49 & $24.49 \%$ & $14.60-38.09 \%$ \\
\hline $\mathrm{pT} 1 \mathrm{pN} 3 \mathrm{c}$ & 0 & 2 & 0 & 2 & $100.00 \%$ & $34.24-100.00 \%$ \\
\hline $\mathrm{pT} 2 \mathrm{pN} 0$ & 506 & 15 & 2 & 523 & $3.25 \%$ & $2.04-5.14 \%$ \\
\hline pT2pN1a & 295 & 20 & 0 & 315 & $6.35 \%$ & $4.15-9.60 \%$ \\
\hline pT2pN2a & 140 & 22 & 1 & 163 & $14.11 \%$ & $9.59-20.28 \%$ \\
\hline pT2pN3a & 96 & 19 & 0 & 115 & $16.52 \%$ & $10.84-24.37 \%$ \\
\hline pT3pN0 & 27 & 2 & 1 & 30 & $10.00 \%$ & $3.46-25.62 \%$ \\
\hline pT3N1a & 24 & 1 & 0 & 25 & $4.00 \%$ & $0.71-19.54 \%$ \\
\hline $\mathrm{pT} 3 \mathrm{pN} 2 \mathrm{a}$ & 29 & 4 & 1 & 34 & $14.71 \%$ & $6.45-30.13 \%$ \\
\hline pT3pN3a & 36 & 14 & 1 & 51 & $29.41 \%$ & $18.71-43.00 \%$ \\
\hline pT4pN0 & 29 & 2 & 0 & 31 & $6.45 \%$ & $1.79-20.72 \%$ \\
\hline pT4pN1a & 20 & 4 & 0 & 24 & $16.67 \%$ & $6.68-35.85 \%$ \\
\hline pT4pN2a & 14 & 4 & 1 & 20 & $25.00 \%$ & $11.19-46.87 \%$ \\
\hline pT4pN3a & 19 & 15 & 1 & 35 & $45.71 \%$ & $30.47-61.81 \%$ \\
\hline pT4pN3b & 0 & 1 & 0 & 1 & $100.00 \%$ & $20.65-100.00$ \\
\hline
\end{tabular}

$\mathrm{M} 1_{12}$ was performed to include patients with subclinical metastases and false-negative results at initial diagnosis. The prevalence was determined for each pathological tumor stage. This retrospective study was approved by the Institutional Review Board (approval number 1130-2011) of the Hannover Medical School and conducted according to all current ethical guidelines.

Statistical analysis. The prevalence of metastases (M1 and $\mathrm{M} 1_{12}$ ) and the corresponding two-sided 95\% Wilson confidence interval (CI) were calculated for each subgroup of pathological tumor stage. A multivariate model investigating the association between the occurrence of metastasis and possible risk factors was created. For patients among whom the risk of metastasis was less than $5 \%$, abandoning routine staging seemed appropriate. Thus, the variable staging abandoned was dichotomized to pT1pN0, pT1pN1a with pT2pN0 versus all other stages in the analysis of M1, and to pT1pN0 versus all other stages in the analysis of $M 1_{12}$. The relevance of the staging abandoned to the occurrence of metastasis was evaluated with logistic regression models. Firstly, a univariate logistic regression model was computed for the tumor stage and for each candidate risk factor separately. In order to adjust the prognostic value of pathological tumor stage for further factors, multivariate logistic regression models were computed including the tumor stage and all factors with a $p$-value of 0.2 or less in the univariate analyses. In order to achieve a small and meaningful model, the number of factors was reduced in a backward selection, where factors remained in the model if the $p$-value was 0.15 or less. The model was checked for multicolinearity among the variables by 

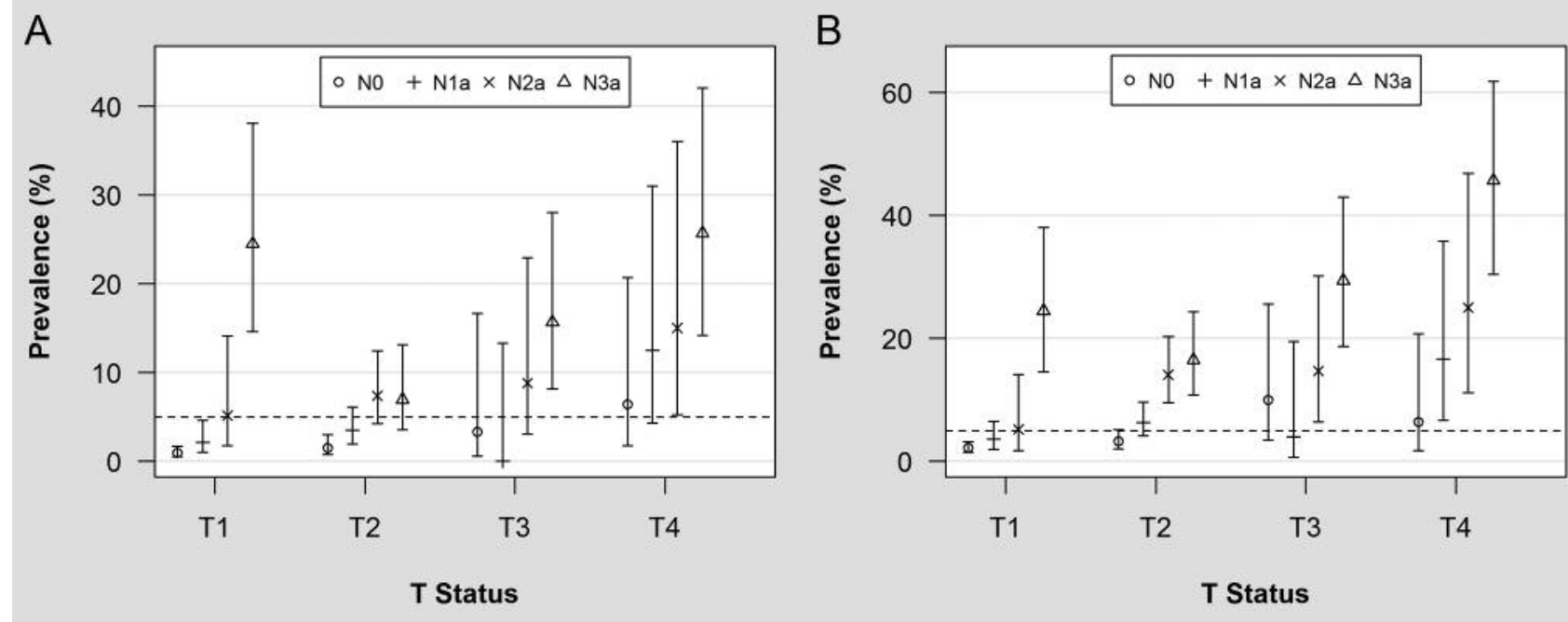

Figure 1. The prevalence of metastases and corresponding confidence intervals are shown for each pathological tumor stage. Metastatic prevalence at initial diagnosis $(\mathrm{M1})(\mathrm{A})$ and at 12 months of follow-up $\left(\mathrm{M1}_{12}\right)(B)$. The upper boundary of the $95 \%$ confidence interval for M1 was less than $5 \%$ for the tumor stages $\mathrm{PT1} 1 \mathrm{pNO}, \mathrm{pT1pN1}$ and $\mathrm{pT2} 2 \mathrm{pNO}$. For $\mathrm{M1}_{12}$, it was less than $5 \%$ for patients with pT1pNO only.

computing the tolerance for each variable regressed on all others in the model. Multicolinearity may exist if the tolerance is less than 0.4 . The results are presented listing absolute and relative frequencies, the odds ratios and their corresponding two-sided $95 \%$ CIs and the two-sided $p$-value. In 24 out of 2906 patients $(0.8 \%)$ the M status was unknown (MX). In the primary analysis, MX was replaced by M1. For statistical analyses, we used SAS ${ }^{\circledR}$, Version, 9.2 and R, Version 2.15.1; SAS Institute Inc., Cary, NC, USA.

\section{Results}

The prevalence of metastases (M1) at initial staging was $3.5 \%$ irrespective of tumor stage. The prevalence of metastases $\left(\mathrm{M}_{12}\right)$ was $6.3 \%$. For tumor stages pT1pN0, pT1pN1 and pT2pN0, M1 was less than $5 \%$. M1 12 was less than $5 \%$ for tumor stage pT1pN0. The prevalences and corresponding CIs are shown for each pathological tumor stage in Tables I and II and Figure 1.

In the majority of patients, only one organ site was involved. Multiple organ sites were involved in 8 out of 79 patients (M1) and 25 out of 169 patients $\left(\mathrm{M} 1_{12}\right)$. Bone metastases were most frequently detected, followed by liver metastases and pulmonary/pleural metastases. The median follow-up was 71 months.

Patients with node-positive breast cancer had a significantly higher risk of distant metastasis than did nodenegative patients in the multivariate analysis at M1, (data not shown) and after 12 months' follow-up $\left(\mathrm{M}_{12}\right)$ (Tables III and IV). In the backward selected model at 12 months' follow-up, the risk of distant metastasis increased with the number of positive axillary lymph nodes (Table IV).
Increasing tumor size was associated with a higher risk of metastasis if patients had a nodal status of $\mathrm{pN} 0, \mathrm{pN} 1$ or $\mathrm{pN} 2$. However, in the analysis of M1, distant metastases were relatively more common in those with small tumors $<\mathrm{pT} 1 \mathrm{c}$ and $\mathrm{pN} 3$ (three out of seven patients) than in those with larger node-positive tumors $\geq \mathrm{pT} 2$ and pN3 (26 out of 202 patients). This finding is consistent with the analysis of $\mathrm{M}_{12}$ (Tables I and II).

No difference between positive and negative hormone receptor status was found in the analysis of M1. However, patients lacking hormone receptor status had a higher risk of metastases. In the analysis of $\mathrm{M} 1_{12}$, patients with positive hormone receptor status had a smaller risk of metastases than those with hormone receptor-negative tumors. Patients with no reported hormone receptor status had a higher risk of metastasis than those with a negative hormone receptor status (Table IV). A trend for reduced risk in those with highly differentiated tumor and an increased risk in those with poorly differentiated cancer was observed (Table IV). In the multivariate analysis of $\mathbf{M}_{12}$, the factor 'staging abandoned' was not included in the model after backward variable selection because this factor is highly associated with the size of the tumor and the nodal status.

\section{Discussion}

Although it is generally accepted that the likelihood of metastasis is extremely low in asymptomatic early breast cancer, routine use of baseline staging still varies considerably (7). Risk assessment of each tumor stage will 
Table III. Baseline patient and disease characteristics at 12 months' follow-up $\left(\mathrm{M1}_{12}\right)$. The frequencies of dichotomous and categorical variables with more than two outcomes after 12 months are presented. Three categories of outcome status of metastasis are distinguished: no distant metastasis $(M 0)$, distant metastasis $\left(M_{12}\right)$ and $M$ status unknown/indeterminate $(M X)$. In the primary analysis, patients with $M X$ were treated as $M 1_{12}$.

\begin{tabular}{|c|c|c|c|c|}
\hline Variable & $\begin{array}{c}\text { Sample size } \\
(\mathrm{N}=2906), \mathrm{n}(\%)\end{array}$ & $\begin{array}{c}\mathrm{M} 0 \\
(\mathrm{~N}=2722), \mathrm{n}(\%)\end{array}$ & $\begin{array}{c}\mathrm{M} 1_{12} \\
(\mathrm{~N}=169), \mathrm{n}(\%)\end{array}$ & $\begin{array}{c}\mathrm{MX} \\
(\mathrm{N}=15), \mathrm{n}(\%)\end{array}$ \\
\hline \multicolumn{5}{|l|}{ Staging abandoned } \\
\hline No & $1753(60.32 \%)$ & $1594(90.93 \%)$ & $150(8.56 \%)$ & $9(0.51 \%)$ \\
\hline Yes & $1153(39.68 \%)$ & $1128(97.83 \%)$ & $19(1.65 \%)$ & $6(0.52 \%)$ \\
\hline \multicolumn{5}{|l|}{ Age } \\
\hline$<60$ Years & $1706(58.71 \%)$ & $1603(93.96 \%)$ & $93(5.45 \%)$ & $10(0.59 \%)$ \\
\hline$\geq 60$ Years & $1200(41.29 \%)$ & $1119(93.25 \%)$ & $76(6.33 \%)$ & $5(0.42 \%)$ \\
\hline \multicolumn{5}{|l|}{ Hormone receptors } \\
\hline Negative & $663(22.81 \%)$ & $601(90.68 \%)$ & $58(8.75 \%)$ & $4(0.60 \%)$ \\
\hline Positive & $2137(73.54 \%)$ & $2029(94.95 \%)$ & $101(4.73 \%)$ & $7(0.33 \%)$ \\
\hline Missing & $106(3.65 \%)$ & $92(86.79 \%)$ & $10(9.43 \%)$ & $4(3.77 \%)$ \\
\hline \multicolumn{5}{|l|}{ HER2 } \\
\hline Negative & $674(23.19 \%)$ & $636(94.36 \%)$ & $34(5.04 \%)$ & $4(0.59 \%)$ \\
\hline Positive & $150(5.16 \%)$ & $141(94.00 \%)$ & $7(4.67 \%)$ & $2(1.33 \%)$ \\
\hline Missing & $2082(71.64 \%)$ & $1945(93.42 \%)$ & $128(6.15 \%)$ & $9(0.43 \%)$ \\
\hline \multicolumn{5}{|l|}{ Grade } \\
\hline 1 & $192(6.61 \%)$ & $190(98.96 \%)$ & $2(1.04 \%)$ & $0(0.00 \%)$ \\
\hline 2 & $1387(47.73 \%)$ & $1321(95.24 \%)$ & $59(4.25 \%)$ & $7(0.50 \%)$ \\
\hline 3 & $1027(35.34 \%)$ & $928(90.36 \%)$ & $94(9.15 \%)$ & $5(0.49 \%)$ \\
\hline 4 & $8(0.28 \%)$ & $5(62.50 \%)$ & $2(25.00 \%)$ & $1(12.50 \%)$ \\
\hline Missing & $292(10.05 \%)$ & $278(95.21 \%)$ & $12(4.11 \%)$ & $2(0.68 \%)$ \\
\hline \multicolumn{5}{|l|}{ Size of tumor } \\
\hline pT1a, pT1b, pT1mi & $429(14.76 \%)$ & $420(97.90 \%)$ & $5(1.17 \%)$ & $4(0.93 \%)$ \\
\hline $\mathrm{pT} 1, \mathrm{pT} 1 \mathrm{c}$ & $1110(38.20 \%)$ & $1067(96.13 \%)$ & $40(3.60 \%)$ & $3(0.27 \%)$ \\
\hline pT2, pT2a, pT2b & $1116(38.40 \%)$ & $1037(92.92 \%)$ & $76(6.81 \%)$ & $3(0.27 \%)$ \\
\hline pT3 & $140(4.82 \%)$ & $116(82.86 \%)$ & $21(15.00 \%)$ & $3(2.14 \%)$ \\
\hline All stages of pT4 & $111(3.82 \%)$ & $82(73.87 \%)$ & $27(24.32 \%)$ & $2(1.80 \%)$ \\
\hline \multicolumn{5}{|l|}{ Nodal status } \\
\hline pNO & $1737(59.77 \%)$ & $1690(97.29 \%)$ & $38(2.19 \%)$ & $9(0.52 \%)$ \\
\hline pN1a & $641(22.06 \%)$ & $606(94.54 \%)$ & $35(5.46 \%)$ & $0(0.00 \%)$ \\
\hline $\mathrm{pN} 2 \mathrm{a}$ & $275(9.46 \%)$ & $238(86.55 \%)$ & $34(12.36 \%)$ & $3(1.09 \%)$ \\
\hline $\mathrm{pN} 3 \mathrm{a}$ & $253(8.71 \%)$ & $188(74.31 \%)$ & $62(24.51 \%)$ & $3(1.19 \%)$ \\
\hline \multicolumn{5}{|l|}{ Year of diagnosis } \\
\hline $1992-1997$ & $915(31.49 \%)$ & $864(94.43 \%)$ & $45(4.92 \%)$ & $6(0.66 \%)$ \\
\hline $1998-2003$ & $1154(39.71 \%)$ & $1067(92.46 \%)$ & $83(7.19 \%)$ & $4(0.35 \%)$ \\
\hline 2004-2009 & $837(28.80 \%)$ & $791(94.50 \%)$ & $41(4.90 \%)$ & $5(0.60 \%)$ \\
\hline
\end{tabular}

help identify those patients who will derive the most benefit from baseline staging.

In our study, the overall prevalence, frequency and location of metastases are in agreement with previous studies $(3,8,9,10,16)$. Our results suggest that the risk of missing metastases in pathological stage I and stage IIA breast cancer is extremely low. In the analysis of $M 1_{12}$, the prevalence of metastases in pathological stage I breast cancer was slightly higher than in the M1 analysis. For pathological stage IIA breast cancer the upper confidence bound was $5.14 \%$, but the prevalence still remained low.

A major concern of baseline screening in early breast cancer is the high rate of false-positive or indeterminate findings $(4,8)$. Overdiagnosis of metastasis is potentially harmful because it can lead to considerable psychological distress and potentially wrong treatment decisions. Indeterminate findings can cause anxiety and generate costly additional investigations. The false-positive rate of bone scans varies between $6 \%$ and $22 \%(4,9,12)$. Routine liver ultrasound has a false-positive rate of $6-7 \%(4,9)$. The limited value of chest $\mathrm{x}$-ray in asymptomatic patients with breast cancer and other tumor entities has been shown in numerous studies (13-16). The false-positive rate of chest $\mathrm{x}$ ray in asymptomatic patients varies between $3-23 \%(3,4,9)$.

The diagnostic accuracy of CT scans is supposedly higher than that of more traditional imaging modalities. Hence, leading international societies endorse the use of chest CT, abdominal ultrasound or abdominal CT scan for baseline 
Table IV. Multivariate primary analysis at 12 months' follow-up (M1 12 ).

\begin{tabular}{lcc}
\hline Model M1 ${ }_{12}$ after backward variable selection $(\mathrm{n}=2,906)$ & \\
\hline Variable & Odds ratio $(95 \% \mathrm{CI})$ & $p$-Value \\
\hline Hormone receptors (ref: negative) & & 0.0005 \\
$\quad$ Positive & $0.646(0.451-0.926)$ & 0.0174 \\
Missing & $2.035(1.031-4.020)$ & 0.0407 \\
Grade (ref: 2) & & 0.0712 \\
1 & $0.338(0.080-1.417)$ & 0.1378 \\
3 & $1.334(0.936-1.902)$ & 0.1105 \\
4 & $4.104(0.785-21.450)$ & 0.0942 \\
Missing & $0.839(0.447-1.576)$ & 0.5859 \\
Tumor size & & \\
(ref: pT1a,pT1b,pT1mi) & & $<0.0001$ \\
pT1, pT1c & $1.423(0.677-2.988)$ & 0.3519 \\
pT2, pT2a, pT2b & $1.688(0.813-3.505)$ & 0.1600 \\
pT3 & $2.428(1.038-5.681)$ & 0.0408 \\
All stages of pT4 & $5.488(2.362-12.751)$ & $<0.0001$ \\
Nodal status (ref: N0) & & $<0.0001$ \\
N1a & $1.822(1.150-2.887)$ & 0.0107 \\
N2a & $4.042(2.492-6.555)$ & $<0.0001$ \\
N3a & $7.560(4.814-11.873)$ & $<0.0001$ \\
\hline
\end{tabular}

CI: Confidence interval. Hormone receptor status, nodal status and the size of tumor were of prognostic value in the multivariate primary analysis of $\mathrm{M} 1_{12}$.

testing $(2,14)$. In a recent study, the value of preoperative CT in detecting lung and liver metastases was investigated (17). Distant metastases were found in $0.2 \%$ of those with stage I breast cancer, while $13.4 \%$ (60 out of 448 ) of the patients had false-positive lesions. None of the 838 patients with stage II breast cancer had lung or liver metastases, while $14.4 \%$ (121 out of 838) of the patients had a false-positive finding. In stage III breast cancer, $6 \%$ (25 out of 417 ) of the findings were true positives and $14.2 \%$ (59 out of 417) were false positives (17). In another recent study, the false-positive rate for the total population was $8.5 \%$ on CT scan and $7.7 \%, 9.0 \%$ and $8.7 \%$ in stages I, II and III, respectively (11).

Due to the retrospective nature of our study, we were not able to accurately determine the false-negative and falsepositive rate of each imaging modality. However, our results indicate that baseline staging in pathological stage I and stage IIA breast cancer would pick up only very few metastases but generate a significant number of false-positive or indeterminate findings. In our study, the prevalence of metastases in pT2pN1 (stage IIB) was $3.49 \%(95 \% \mathrm{CI}=1.96-6.14 \%)$ in the analysis of $\mathrm{M} 1$ and $6.35 \%(95 \% \mathrm{CI}=4.15-9.60 \%)$ in the analysis of $\mathrm{M} 1_{12}$. Given a false-positive rate of $9-14 \%$ in stage II breast cancer, the risk of overdiagnosing metastasis is higher than the chance of detecting true metastatic disease $(11,17,18)$. For pT2pN1, the benefit of baseline staging must be carefully weighed against the potential disadvantages. Missing metastases is clearly an unfortunate event, but the risk of undertreatment is highly unlikely. In contrast to this, falsepositive findings do carry the risk of undertreatment. Patients with assumed metastatic disease will only receive palliative, instead of curative treatment.

The prevalence of metastases (M1) in pT3pN0 (stage IIB) tumors was $3.3 \%(95 \% \mathrm{CI}=0.59-16.67 \%)$ and $10 \%(95 \%$ $\mathrm{CI}=3.46-25.62 \%)$ in the analysis of $\mathrm{M} 1_{12}$, respectively. The accurate prevalence of metastases remains indeterminate for this subgroup and the remaining higher tumor stages due to the small numbers of patients and the large variability seen in the CIs.

The multivariate analysis points to the importance of tumor biology, suggesting that node-positive, hormone receptor-negative, large breast carcinomas are associated with an increased risk of distant metastasis. It is of interest to note that small tumors $(<\mathrm{pT} 1 \mathrm{c} p \mathrm{pN} 3)$ with extensive axillary lymph node involvement tended to have a markedly increased risk of distant metastasis. Previous studies have shown that breast cancer subtypes are associated with unique patterns of metastatic spread with notable differences in survival (19). However, a limitation of our study is the variability of methods used to determine the hormone receptor status. During the era of this cohort, the methods, thresholds for positivity and interpretation criteria have changed significantly. In addition the HER2/neu status was unknown in the majority of our patients.

In conclusion, our results support current guidelines according to which baseline staging can be safely abandoned in asymptomatic patients with pathological stage I and IIA breast cancer. The lowest risk of distant metastasis was observed in hormone receptor-positive, G1/G2, pT1pN0 breast cancer. The risk of distant metastasis is somewhat higher for pT2pN1 (stage IIB) breast cancer. However, with the considerable risk of false or indeterminate findings in mind, it is appropriate to abandon routine baseline staging for this subgroup. Baseline staging should remain part of clinical work-up in pT3pN0 (stage IIB) cancer and higher stages.

\section{Ethical Standards}

This retrospective study was approved by the Institutional Review Board of the Hannover Medical School and conducted according to all current ethical guidelines. The experiments/methods used comply with the current laws of Germany.

\section{Conflicts of Interest}

The Authors declare that they have no conflict of interest.

\section{Acknowledgements}

The Authors would like to acknowledge and thank the staff at the Cancer Registry, Hannover Medical School for their support and efforts. This study was supported, in part, by the Claudia von Schilling Foundation for Breast Cancer Research Germany. 


\section{References}

1 Carlson RW, Allred DC, Anderson BO, Burstein HJ, Carter WB, Edge SB, Erban JK, Farrar WB, Forero A, Giordano SH, Goldstein LJ, Gradishar WJ, Hayes DF, Hudis CA, Ljung BM, Mankoff DA, Marcom PK, Mayer IA, McCormick B, Pierce LJ, Reed EC, Sachdev J, Smith ML, Somlo G, Ward JH, Wolff AC, Zellars $\mathrm{R}$ and National Comprehensive Cancer N: Invasive breast cancer. J Natl Compr Canc Netw 9: 136-222, 2011.

2 Senkus E, Kyriakides S, Penault-Llorca F, Poortmans P, Thompson A, Zackrisson S and Cardoso F: Primary breast cancer: ESMO Clinical Practice Guidelines for diagnosis, treatment and follow-up. Ann Oncol Suppl 6: 7-23, 2013.

3 Myers RE, Johnston M, Pritchard K, Levine M, Oliver T and Breast Cancer Disease Site Group of the Cancer Care Ontario Practice Guidelines I: Baseline staging tests in primary breast cancer: a practice guideline. CMAJ 164: 1439-1444, 2001.

4 Puglisi F, Follador A, Minisini AM, Cardellino GG, Russo S, Andreetta C, Di Terlizzi S and Piga A: Baseline staging tests after a new diagnosis of breast cancer: further evidence of their limited indications. Ann Oncol 16: 263-266, 2005.

5 Kühn T, Alber, U-S, Bick U, Degenhardt F, Kreienberg R, Kreipe H, Lebeau A, Madjar H and Schreer I: Interdisziplinäre S3-Leitlinie für die Diagnostik, Therapie und Nachsorge des Mammakarzinoms. Kreienberg R (ed.). Munich, Zuckschwerdt, pp. 59-61, 2012.

6 Singletary SE, Allred C, Ashley P, Bassett LW, Berry D, Bland KI, Borgen PI, Clark GM, Edge SB, Hayes DF, Hughes LL, Hutter RV, Morrow M, Page DL, Recht A, Theriault RL, Thor A, Weaver DL, Wieand HS and Greene FL: Staging system for breast cancer: revisions for the 6th edition of the AJCC Cancer Staging Manual. Surg Clin North Am 83: 803-819, 2003.

7 Chand N, Cutress RI, Oeppen RS and Agrawal A: Staging Investigations in Breast Cancer: Collective Opinion of UK Breast Surgeons. Int J Breast Cancer 2013: 506172, 2013.

8 Gerber B, Seitz E, Muller H, Krause A, Reimer T, Kundt G and Friese K: Perioperative screening for metastatic disease is not indicated in patients with primary breast cancer and no clinical signs of tumor spread. Breast Cancer Res Treat 82: 29-37, 2003.

9 Muller D, Kohler G and Ohlinger R: Staging procedures in primary breast cancer. Anticancer Res 28: 2397-2400, 2008.

10 Ravaioli A, Pasini G, Polselli A, Papi M, Tassinari D, Arcangeli V, Milandri C, Amadori D, Bravi M, Rossi D, Fattori PP, Pasquini $\mathrm{E}$ and Panzini I: Staging of breast cancer: new recommended standard procedure. Breast Cancer Res Treat 72: 53-60, 2002.
11 Tanaka S, Sato N, Fujioka H, Takahashi Y, Kimura K, Iwamoto $\mathrm{M}$ and Uchiyama $\mathrm{K}$ : Use of contrast-enhanced computed tomography in clinical staging of asymptomatic breast cancer patients to detect asymptomatic distant metastases. Oncol Lett 3: 772-776, 2012.

12 Wikenheiser KA and Silberstein EB: Bone scintigraphy screening in stage I-II breast cancer: is it cost-effective? Cleve Clin J Med 63: 43-47, 1996.

13 Glynne-Jones R, Young T, Ahmed A, Ell PJ and Berry RJ: How far investigations for occult metastases in breast cancer aid the clinician. Clin Oncol (R Coll Radiol) 3: 65-72, 1991.

14 Hurria A, Leung D, Trainor K, Norton L and Hudis C: Screening chest imaging studies are not effective in the follow-up of breast cancer patients. J Oncol Manag 12: 13-15, 2003.

15 Terhune MH, Swanson N and Johnson TM: Use of chest radiography in the initial evaluation of patients with localized melanoma. Arch Dermatol 134: 569-572, 1998.

16 Tsao H, Feldman M, Fullerton JE, Sober AJ, Rosenthal D and Goggins W: Early detection of asymptomatic pulmonary melanoma metastases by routine chest radiographs is not associated with improved survival. Arch Dermatol 140: 67-70, 2004.

17 Kim H, Han W, Moon HG, Min J, Ahn SK, Kim TY, Im SA, Oh DY, Han SW, Chie EK, Ha SW and Noh DY: The value of preoperative staging chest computed tomography to detect asymptomatic lung and liver metastasis in patients with primary breast carcinoma. Breast Cancer Res Treat 126: 637-641, 2011.

18 Barrett T, Bowden DJ, Greenberg DC, Brown CH, Wishart GC and Britton PD: Radiological staging in breast cancer: which asymptomatic patients to image and how. Br J Cancer 101: 1522-1528, 2009.

19 Kennecke H, Yerushalmi R, Woods R, Cheang MC, Voduc D, Speers CH, Nielsen TO and Gelmon K: Metastatic behavior of breast cancer subtypes. J Clin Oncol 28: 3271-3277, 2010. 